\title{
Analisis Penjualan E-Tiket Menggunakan Algoritma Apriori Pada Cv.Guti Mulia Wisata
}

\author{
Wirdah Choiriah ${ }^{1}$ \\ (Program Studi Teknik Informatika Fakultas Ilmu Komputer Universitas Lancang Kuning) \\ (Jl. Yos Sudarso KM. 8 Rumbai, Pekanbaru, Riau, telp. 085264622858) \\ e-mail: wirdah@unilak.ac.id
}

\begin{abstract}
Abstrak
Seiring dengan zaman yang serba digital, sebagian besar maskapai sudah memberlakukan sistem online booking. Menyesuaikan hal ini, tiket model lama pun mulai dialihkan menjadi etiket atau e-ticket (electronic ticket). Di bandara, penumpang yang membawa tiket model lama sudah semakin sedikit dibanding pengguna e-tiket pesawat. Seiring dengan kemajuan teknologi serta inovasi baru, sistem e-ticket dikembangkan pada model transportasi. Analisis Penjualan E-Tiket Menggunakan Algoritma Apriori Pada Cv.Guti Mulia wisata tujuannya adalah mendeskrisipan makna pemanfaatan eletronik tiket atau e-ticket yang digunakan oleh para pengguna.Penelitian ini memaparkan pula motif-motif pemanfaatan elektronik tiket dan juga tanggapan layanan e-tickting.latar belakang pengalaman antri, kemudahan dalam pembelian tiket (Aksesbilitas) dan juga ketepatan penyampaian informasi (Validitas). Selain itu, Persepsi tentang layanan yang diberikan Cv.Guti Mulia wisata, pengguna mengakui cukup puas dan juga kurang puas terhadap layanan e-ticket. Sebagian pengguna yang mengaku puas berpendapat bahwa sistem online tiket saat ini yang mempermudah calon penumpang yang akan membeli tiket. Sementara mengaku kurang puas dengan layanan e-ticket banyak yang mengeluhkan tentang komputer yang digunakan eror saat melakukan proses online tiket sehingga harus mengulang prosesnya.
\end{abstract}

Kata kunci: E-tiket (elektronic ticket), Algorithma Apriori, Data Mining

\begin{abstract}
Along with the digital age, most airlines have implemented an online booking system. Adjusting this, the old model tickets began to be transferred to etiquette or e-ticket (electronic ticket). At the airport, passengers who carry old model tickets are getting fewer compared to eticket users. Along with advances in technology and new innovations, e-ticket systems are developed in the transportation model. Analysis of E-Ticket Sales Using Apriori Algorithm In Cv.Guti Mulia Wisata the purpose is to describe the meaning of using electronic tickets or etickets used by users. This research also describes the motives of electronic ticket utilization and e-tickting service responses. background of queuing experience, ease of purchasing tickets (accessibility) and also the accuracy of information delivery (validity). In addition, Perception about the services provided by Cv.Guti Mulia Wisata, users admitted that they were quite satisfied and also not satisfied with e-ticket services. Some users who claim to be satisfied argue that the current online ticket system makes it easier for prospective passengers who will buy tickets. While claiming to be less satisfied with the e-ticket service, many complained about the computer being used for errors while processing the ticket online so they had to repeat the process.
\end{abstract}

Keywords: E-tiket (elektronic ticket),Algorithma Apriori,Data Mining 


\section{Pendahuluan}

Bisnis dalam industri travel semakin berkembang jika didukung dengan sistem pemesanan tiket menggunakan media internet yang dilakukan secara online.Pemesanan tiket secara online memberikan kemudahan bagi konsumen dalam banyak hal seperti kemudahan pencarian informasi jadwal perjalanan dan harga tiket. Selain itu, konsumen dapat melakukan pemesanan tiket kapan saja dan dimana saja tanpa harus datang ke biro travel agent yang bersangkutan Beberapa hal tersebut adalah manfaat positif dari penggunaan teknologi informasi. Pemesanan tiket secara online memberikan kemudahan bagi konsumen dalam banyak hal seperti kemudahan pencarian informasi jadwal perjalanan dan harga tiket.Selain itu, konsumen dapat melakukan pemesanan tiket kapan saja dan dimana saja tanpa harus datang ke biro travel agent yang bersangkutan. Saat ini tiket elektronik telah menggantikan fungsi tiket pesawat konvensional yang biasanya terdiri atas beberapa kertas dan umumnya maskapai penerbangan memberlakukan biaya tambahan untuk melakukan pengeluaran tiket menggunakan jenis tiket ini.

Beberapa hal tersebut adalah manfaat positif dari penggunaan teknologi informasi.Semakin banyak jumlah travel yang berkembang saat ini membuat para pengelola ingin menunjukkan strategi pemasaran yag lebih baik. Untuk itu maka para pengelola harus mencermati pola- pola pembelian yang dilakukan oleh konsumen. Seperti pola penjualan tiket pesawat pada CV. Guti Mulia Wisata yang penulis amati ketika memesan tiket disana. Permasalahan yang sering timbul pada pemesanan tiket pesawat adalah tiket yang pemesan inginkan tidak ada atau habis karena mereka kurang mengamatai transaksi yang ada. Hal itu tentu sangant mengecewakan konsumen yang hendak memesan tiket pesawat. Didunia penjualan, para pengembang dituntut agar dapat menemukan suatu formula yang dapat meningkatkan penjualan produk dipasar. Salah satu cara yaitu dengan memanfaatkan data penjualan setiap hari. Dengan menggunakan data yang diperoleh setiap hari dapat dimanfaatkan dan diolah menjadi suatu informasi yang berguna untuk peningkatan penjualan dan promosi produk.

Agar memudahkan mengolah data yang telah ada dengan jumlah yang sangat banyak, digunakan data mining. Dengan menggunakan data mining maka akan didapatkan suatu pengetahuan didalam kumpulan data-data yang banyak tersebut. Salah satu penerapan data mining adalah dibidang penjualan produk. Kemudian Algoritma apriori adalah algoritma pengambilan data dengan aturan asosiatif (Association rule) untuk menentukan hubungan asosiatif suatu kombinasi item. Association Rule yang dimaksud dilakukan melalui mekanisme penghitungan support dan confidence dari suatu hubungan item. Sebuah rule asosiasi dikatakan interesting jika nilai support adalah lebih besar dari minimum support dan juga nilai confidence adalah lebih besar dari minimum confidence. Dengan demikian perusahaan dapat memanfaatkan kumpulan data lama menjadi swatu pengetahuan baru untuk menentukan strategi pemasaran yang lebih baik.

\section{Metode Penelitian}

\subsection{E-Tiket}

Dalam maskapai penerbangan, tiket merupakan sarana untuk bisa menjual jasa penerbangan kepada penumpang atau konsumen. Menurut surat keputusan mentri Perhubungan Nomor 25 Tahun 2008 tentang penyelenggaraan angkutan udara yang,yang dimksud dengan tiket yaitu dokumen cetak yang merupakan salah satu bukti adanya perjanjian pengangkutan udara anatara penumpang dengan pengangkut. Kemudia menurut undang undang Republik Indonesia Nomor 1 tahun 2009 tentang Penerbangan, yang dimaksud dengan tiket yaitu dokumen berbentuk cetak, melalui proses elektronik, atau bentuk lainnya, yang merupakan salah satu alat bukti adanya perjanjian angkutan udara dengan penumpang ${ }_{[1]}$. 
Tiket elektronik (e-ticket) sebuah tiket yang berbentuk digital, tiket elektronik dapat digunakan untuk penerbangan,kereta api,bus, dan lain sebagainya. Pada tangal 1 juni 2009, IATA (International Air Transport Association) telah mmberikan mandat kepada setiap anggotanya agar menggunakan tiket elektronik dalam segala bentuk pembayaran. pengaruh eticketing technique yang terdiri dari customer technical support, infrastructure, data security, user-friendliness terhadap kepuasan konsumen. [2]. Berdasarkan model hubungan antara e-ticketing technique (customer technical support, infrastructure, data security,user-friendliness) dengan kepuasan konsumen E-ticketing technique (customer technical support, infrastructure, data security, user-friendliness) memiliki pengaruh yang positif dasignifikan terhadap kepuasan konsumen. Berdasarkan model hubungan antara kepuasan konsumen dengan Word of Mouth dan Niat pembelian ulang (Repurchase Intention) [3] · Kepuasan konsumen memiliki pengaruh yang positif dan signifikan terhadap niat pembelian ulang pada konsumen (Repurchase Intention) . Berdasarkan model hubungan antara kepuasan konsumen dengan word of mouth ${ }_{\text {[4] }}$.

\subsection{Data Mining}

Data mining merupakan suatu proses pendukung pengambil keputusan dimana kita mencari pola informasi dalam data. Pencarian ini dapat dilakupengguna, misalnya dengan menggunakan query atau dapat dibantu dengan suatu aplikasi yang secara otomatis mencari pola informasi pada basis data. Pencarian ini disebut discovery ${ }_{[5]}$. Data mining sering juga disebut knowledge discovery in database (KDD), adalah kegiatan yang meliputi pengumpulan, pemakaian data historis untuk menemukan keteraturan, pola atau hubungan dalam set data berukuran besar. Keluaran dari data mining ini bisa dipakai untuk memperbaiki pengambilan keputusan di masa depan. Sehingga istilah pattern recognition sekarang jarang digunakan karena termasuk bagian dari data mining ${ }_{[6]}$. Pada dasarnya ada enam elemen yang paling esensial dalam teknik pencarian .informasi/pengetahuan dalam KDD yaitu:

1. Mengerjakan sejumlah besar data.

2. Diperlukan efesiensi berkaitan dengan volumedata.

3. Mengutamakan ketetapan/keakuratan.

4. Membutuhkan pemakaian bahasa tingkat tinggi.

5. Menggunakan beberapa bentuk dari pembelajaranotomatis.

6. Menghasilkan hasil yang menarik

\subsection{AlgoritmaApriori}

Algoritma Apriori adalah suatau algoritma dasar yang diusulkan oleh Agrawal dan Srikant pada tahun 1994 untuk penentuan Frequent itemsets untuk aturan asosiasi boolean. Algoritma apriori termasuk jenis aturan asosiasi pada data mining ${ }_{[7]}$. Aturan yang menyatakan asosiasi antara beberapa atribut sering disenbut affinity analysis atau market basket analysis. Analisis asosiasi atau association rule mining adalah teknik data mining untuk menemukan aturan suatu kombinasi item. Salah satu tahap analisis asosiasi yang menarik perhatian banyak peneliti untuk menghasilkan algoritma yang efisien adalah analisis pola frequensi tinggi (frequent pattern mining). Penting tidaknya suatu asosiasi dapat diketahui dengan dua tolak ukur, yaitu : support dan confidence. Support (nilai penunjang) adalah persentase kombinasi item tersebut dalam database, sedangkan confidence (nilai kepastian) adalah kuatnya hubungan antar-item dalam aturan asosiasi ${ }_{[8]}$ 
Analisis Pola Frekuensi Tinggi dengan Algoritma AprioriTahap ini mencari kombinasi item yang memenuhi syarat minimum dari nilai support dalam basis data . nilai support sebuah item diperoleh dengan menggunakan rumus sebagai berikut:

$$
\operatorname{Support}(A, B)=\frac{\text { Jumlah transaksi mengandung nilai A }}{\text { Total Transaksi }}
$$

\section{Total Transaksi}

Sementara, nilai support dari 2 item dioeroleh dengan menggunakan rumus berikut :

$$
\begin{aligned}
& \text { Support }(A, B)=P(A \cap B) \\
& \text { Support }(A, B)=\frac{\sum \text { transaksi mengandung AdanB }}{\sum \text { transaksi }}
\end{aligned}
$$

Frequent itemset menunjukkan itemset yang memiliki frekuensi kemunculan lebihdari nilai minimum yang ditentukan ().Misalkan $=2$, maka semua itemsets yangfrekuensi kemunculannya lebih dari atausama dengan 2 kali disebut frequent.Himpunan dari frequent kitemset dilambangkan dengan Fk.

Setelah semua pola frekuensi tinggi ditemukan, barulah dicari aturan asosiasi yang memenuhi syarat minimum untuk confidence dengan menghitung confidence atuan asosiatif $\mathrm{A} \rightarrow \mathrm{B}$. Nilai confidence dari aturan $\mathrm{A} \rightarrow \mathrm{B}$ diperoleh dengan rumus berikut:

$$
\text { Confidence }=P(A / B)=\frac{\sum \text { transaksi mengandung Adan } B}{\sum \text { transaksi mengandung } A}
$$

Untuk menentukan aturan asosiasi yang akan di pilih maka harus diurutkan berdasarkan support * confidence. Aturan sebanyak n aturan yang memiliki hasil terbesar ${ }_{[9]}$.

\section{Hasil dan Pembahasan Implementasi Algoritma Apriori}

Tahapan proses pengolahan data yang dapat dilakukan pada algoritma apriori dengan masukkan dari pengolahan data kemudian di proses pembentukan itemset sehingga menghasilkan kombinasi yang terpilih.

\subsection{Daftar Jeis Tiket Pesawat Pada CV. Guti Mulia Wisata}

Berikut adalah daftar jenis tiket pesawat dan kode maskapai yang ada pada CV.Guti Mulia Wisata, Sebagai sample diambil berdasarkan data transaksi pada bulan oktober 2018 sampai januari 2019 berlaku untuk semua jenis tiket ata u Maskapai penerbangan dan dilakukan akumulasi transaksi penjualan.

Tabel 1: Daftar Maskapai dan jenis tiket pesawat

\begin{tabular}{|c|l|c|}
\hline No. & \multicolumn{1}{|c|}{$\begin{array}{c}\text { Jenis } \\
\text { Tiket Pesawat }\end{array}$} & Kode Maskapai \\
\hline 1. & LION & JT \\
\hline 2. & Batik & ID \\
\hline 3. & Wings & IW \\
\hline 4. & Garuda & GA \\
\hline 5. & Citilink & QG \\
\hline 6. & Air Asia & AK \\
\hline 7. & Sriwijaya & SJ \\
\hline
\end{tabular}


Tabel 2 : Tabel Transaksi pada bulan januari 2019

\begin{tabular}{|c|l|c|}
\hline No. & \multicolumn{1}{|c|}{$\begin{array}{c}\text { Jenis Tiket Pesawat dan Kode } \\
\text { Maskapai }\end{array}$} & $\begin{array}{c}\text { Jumalah } \\
\text { Tiket Terjual }\end{array}$ \\
\hline 1. & LION = JT & 57 \\
\hline 2. & Batik = ID & 44 \\
\hline 3. & Wings = IW & 8 \\
\hline 4. & Garuda = GA & 27 \\
\hline 5. & Citilink = QG & 35 \\
\hline 6. & Air Asia = AK & 20 \\
\hline 7. & Sriwijaya = SJ & 10 \\
\hline & Total & 201 \\
\hline
\end{tabular}

Tabulasi Data Transaksi Pada data transaksi penjualan sparepart dibentuk tabel tabular yang akan memudahkan dalam mengetahui beberapa banyak item yang dibeli disetiap tansaksi.

Tabel 3. Tabel tabular transaksi

\begin{tabular}{|c|c|c|c|c|c|c|c|}
\hline Transaksi & $\begin{array}{c}\text { LION } \\
(\mathbf{J T})\end{array}$ & $\begin{array}{c}\text { Batik } \\
(\mathbf{I D})\end{array}$ & $\begin{array}{c}\text { Wings } \\
(\mathbf{I W})\end{array}$ & $\begin{array}{c}\text { Garuda } \\
(\mathbf{G A})\end{array}$ & $\begin{array}{c}\text { Citilink } \\
(\mathbf{Q R})\end{array}$ & $\begin{array}{c}\text { Air Asia } \\
(\mathbf{A K})\end{array}$ & $\begin{array}{c}\text { Sriwijaya } \\
(\mathbf{S J})\end{array}$ \\
\hline 1 & 1 & 0 & 0 & 1 & 0 & 1 & 0 \\
\hline 2 & 0 & 0 & 1 & 0 & 1 & 0 & 0 \\
\hline 3 & 1 & 1 & 0 & 0 & 0 & 1 & 1 \\
\hline 4 & 0 & 0 & 1 & 1 & 1 & 0 & 0 \\
\hline 5 & 1 & 1 & 0 & 0 & 0 & 1 & 0 \\
\hline 6 & 0 & 0 & 0 & 1 & 1 & 0 & 0 \\
\hline 7 & 1 & 0 & 0 & 0 & 0 & 0 & 0 \\
\hline 8 & 1 & 1 & 0 & 1 & 0 & 1 & 0 \\
\hline 9 & 1 & 0 & 0 & 0 & 1 & 1 & 1 \\
\hline 10 & 1 & 1 & 1 & 0 & 0 & 1 & 0 \\
\hline 11 & 1 & 0 & 0 & 1 & 0 & 0 & 0 \\
\hline 12 & 1 & 1 & 0 & 0 & 0 & 0 & 0 \\
\hline 13 & 1 & 1 & 0 & 1 & 1 & 1 & 1 \\
\hline 14 & 1 & 1 & 0 & 0 & 1 & 0 & 0 \\
\hline 15 & 1 & 1 & 0 & 1 & 1 & 1 & 0 \\
\hline 16 & 1 & 0 & 1 & 0 & 0 & 1 & 1 \\
\hline 17 & 1 & 1 & 0 & 0 & 0 & 1 & 0 \\
\hline 18 & 1 & 1 & 0 & 0 & 0 & 0 & 0 \\
\hline 19 & 0 & 1 & 1 & 1 & 0 & 0 & 0 \\
\hline 20 & 0 & 1 & 0 & 0 & 1 & 0 & 1 \\
\hline 21 & 0 & 1 & 0 & 1 & 0 & 0 & 0 \\
\hline 22 & 1 & 0 & 1 & 0 & 1 & 0 & 0 \\
\hline 23 & 0 & 1 & 0 & 1 & 0 & 1 & 0 \\
\hline 24 & 1 & 0 & 0 & 0 & 1 & 0 & 0 \\
\hline 25 & 0 & 0 & 1 & 0 & 0 & 1 & 1 \\
\hline 26 & 1 & 0 & 0 & 1 & 0 & 0 & 0 \\
\hline 27 & 0 & 1 & 0 & 0 & 1 & 1 & 0 \\
\hline 28 & 1 & 1 & 1 & 1 & 0 & 0 & 1 \\
\hline 29 & 1 & 0 & 0 & 0 & 0 & 1 & 1 \\
\hline & & & & & & & \\
\hline
\end{tabular}




\begin{tabular}{|c|c|c|c|c|c|c|c|}
\hline 30 & 1 & 0 & 0 & 1 & 1 & 0 & 1 \\
\hline 31 & 0 & 0 & 0 & 0 & 0 & 0 & 0 \\
\hline 32 & 0 & 0 & 0 & 1 & 1 & 0 & 0 \\
\hline 33 & 0 & 1 & 0 & 0 & 0 & 0 & 1 \\
\hline 34 & 0 & 1 & 0 & 1 & 1 & 0 & 0 \\
\hline 35 & 0 & 1 & 0 & 0 & 0 & 0 & 0 \\
\hline 36 & 0 & 0 & 0 & 0 & 0 & 0 & 1 \\
\hline 37 & 1 & 0 & 0 & 1 & 0 & 0 & 0 \\
\hline 38 & 1 & 0 & 0 & 0 & 0 & 0 & 1 \\
\hline 39 & 0 & 0 & 0 & 1 & 0 & 0 & 1 \\
\hline 40 & 1 & 0 & 0 & 0 & 0 & 0 & 0 \\
\hline 41 & 1 & 0 & 0 & 0 & 0 & 0 & 0 \\
\hline 42 & 1 & 0 & 0 & 1 & 0 & 0 & 0 \\
\hline 43 & 0 & 0 & 0 & 0 & 0 & 0 & 0 \\
\hline 44 & 1 & 0 & 0 & 1 & 0 & 0 & 1 \\
\hline 45 & 1 & 0 & 0 & 0 & 0 & 0 & 0 \\
\hline 46 & 1 & 0 & 0 & 0 & 0 & 0 & 0 \\
\hline 47 & 0 & 0 & 0 & 1 & 0 & 0 & 0 \\
\hline 48 & 0 & 0 & 0 & 0 & 0 & 0 & 0 \\
\hline 49 & 1 & 0 & 0 & 0 & 0 & 0 & 0 \\
\hline 50 & 0 & 0 & 0 & 1 & 0 & 0 & 0 \\
\hline$\ldots$ & 0 & 0 & 0 & 0 & 0 & 0 & 0 \\
\hline 100 & 1 & 0 & 0 & 1 & 0 & 0 & 0 \\
\hline$\ldots$ & 0 & 0 & 0 & 0 & 0 & 0 & 1 \\
\hline 150 & 1 & 0 & 0 & 0 & 0 & 0 & 0 \\
\hline.. & 0 & 0 & 0 & 0 & 0 & 0 & 1 \\
\hline 200 & 1 & 0 & 0 & 0 & 0 & 0 & 0 \\
\hline 201 & 1 & 0 & 0 & 0 & 0 & 0 & 0 \\
\hline jumlah & $\mathbf{5 7}$ & $\mathbf{4 4}$ & $\mathbf{8}$ & $\mathbf{2 7}$ & $\mathbf{3 5}$ & $\mathbf{2 0}$ & $\mathbf{1 0}$ \\
\hline & & & & & & & \\
\hline & & & 0 & 0 & 0 & 0 \\
\hline
\end{tabular}

a. Pembentukan itemset

Berikut ini adalah penyelesaian dengan contoh kasus berdasarkan data yang sudah disediakan pada tabel transaksi. Proses pembentukan $\mathrm{C}_{\text {。 }}$ atau disebut dengan 2 itemset dengan jumlah minimum support $=30 \%$. Calon 2-itemset.

Tabel 4 : kombinasi 2 itemset

\begin{tabular}{|c|c|c|}
\hline Item et & jumlah & $\begin{array}{c}\text { Jumalah } \\
\text { Tiket Terjual }\end{array}$ \\
\hline JT, ID & 6 & $50 \%$ \\
\hline ID, QG & 5 & $41,67 \%$ \\
\hline IW, ID & 4 & $32,5 \%$ \\
\hline JT, QG & 3 & $25 \%$ \\
\hline QG, GA & 5 & $33,33 \%$ \\
\hline AK, QG & 2 & $10 \%$ \\
\hline SJ, JT & 2 & $10 \%$ \\
\hline
\end{tabular}


b. Pembentukan 3 itemset

Proses Pembentukan $\mathrm{C} 3$ atau disebut 3 itemset dengan jumlah minimum $30 \%$

Tabel 4 : kombinasi 3 itemset

\begin{tabular}{|c|c|c|}
\hline Item et & jumlah & $\begin{array}{c}\text { Jumalah } \\
\text { Tiket Terjual }\end{array}$ \\
\hline JT, ID,QS & 2 & $16,6 \%$ \\
\hline ID,GA,QG & 2 & $16,6 \%$ \\
\hline AK,JT,ID & 2 & $16,6 \%$ \\
\hline JT,GA,WI & 1 & $8,33 \%$ \\
\hline QG, GA, JT & 2 & $16,6 \%$ \\
\hline AK, QG,W1 & 0 & $0 \%$ \\
\hline SJ, JT,AK & 0 & $0 \%$ \\
\hline
\end{tabular}

\section{c. Aturan Asosiasi Final}

Aturan asosiasi final terurut bberdasarkan minimal support dan minimum confidence yang telah ditentukan, dapat dilihat pada tabel dibawah ini:

Tabel 5: Nilai konfidence

\begin{tabular}{|l|l|l|}
\hline Aturan & support & confidence \\
\hline $\begin{array}{l}\text { Jika Membeli Tiket Pesawat Lion (JT), } \\
\text { Maka akan membeli Tiket Psawat Batik (ID) }\end{array}$ & $50 \%$ & $85,71 \%$ \\
\hline $\begin{array}{l}\text { Jika Membeli Tiket Pesawat Lion (JT), } \\
\text { Maka membeli Tiket Pesawat Citilink }\end{array}$ & $50 \%$ & $66,6 \%$ \\
\hline
\end{tabular}

Maka Jenis Tiket Pesawat yang paling banyak Terjual adalah tiket Pesawat Lion air dan tiket pesawat Batik air, dengan demikian perusahaan dapat menyusun strategi pemasaran.

\section{Kesimpulan}

\subsection{Kesimpulan}

Dari uraian diatas maka dapat diambil kesimpulan sebagai berikut :

Data mining sangat berguna untuk mengetahui hubungan pola frekuensi penjualan tiket yang sering dibeli oleh konsumen. Data mining merupakan teknologi yang sangat berguna unuk membantu perusahan untuk menemukan informasi yang sangat penting yang selama ini tidak diketahui manfaatnya. Tanagra Merupakan softwere data mining yang dapat mengolah dan menguji data, dan Algoritma Apriori dpat di terapkan untuk menemukan hasil atau menentukan hasil nilai support dan confiden

\subsection{Saran}

Kemudahan bagi konsumen untuk dilayani melalui telepon, sms, email didalam pemesanan e-tiket harus mendapat perhatian dan perlu ditingkatkan. Memberikan informasi yang lebih detail mengenai jasa layanan yang dijual, seperti harga, sistem pembayaran, kapan produk atau jasa layanan dapat diterima konsumen, garansi yang diberikan. Menyediakan tenaga jasa layanan informasi layanan maupun pengaduan, dan komplain atas kuranginya informasi.Penulis juga menyarankan pada penelitian sejenis dimasa yang akan datang untuk menambahkan beberapa variabel yang relevan mempresiksi perubahan kepuasan konsumen, word of mout. 


\section{Daftar Pustaka}

[1] Margaretha Puspita Aviantari Loven J. Elyawati.Pengaruh Teknik E-ticketing Terhadap Kepuasan Dan Dampak Terhada Niat Pembelian Ulang Dan Wom. Yogyakarta 2017.

[2] Kyauk, Sai.Tip,. Chaipoopirutana,Sirion. Factor Influencing Repurchase Intention(A Case Study of Xyz.com Online Shopping in Myanmar. International Conference on Trends in Economics, Humanities and Management (ICTEHM'14).Pattaya (Thailand). 2014.

[3] Haryono, Sigit,Suharyono, Fauzi Ahmad, dan Suyadi Imam. 2015. The Effect of Service Quality on Costumer Satisfaction, Consumer Delight, Trust,Repurchase Intention,Word of Mouth.Europea Journal of Business and Management www.iiste.org. ISSN 2222-1905 (Paper) ISSN 2222-2839 (Online) Vol.7, No.12, 2015.

[4] Mpinganjira, Mercy.. Enhancing trust in online business relationships of South Africa:a web interface signalling perspective. JournalProblems and Perspectives in Management, Volume 13, Issue 3. 2015.

[5] Beta, N., \& Nurdin, B. (2010). Implementasi data Mining Untuk Menemukan Pola Hubungan Tingkat Kelulusan Mahasiswa Dengan Data Induk Mahasiswa. Prosiding Seminar dan Call Paper Munas APTIKOM Politeknik Telkom Bandung, 09 Oktober 2010.

[6] Kusrini, 2007, Penerapan Algoritma Apriori pada Data Mining untuk Mengelompokkan Barang Berdasarkan Kecenderungan Kemunculan Bersama dalam Satu Transaksi, http://dosen.amikom.ac.id/../Publikasi\%20Aprio ri-Kusrini_Feb-13_.pdf, [diakses 24 Januari 2017].

[7] Dewi K. Pane,.Jurnal : Implementasi Data Mining Pada Penjualan ProdukElektronik Dengan Algoritma Apriori(Studi Kasus : Kreditplus). 2013

[8] Bijaksana, Dhinta Darmantoro. Data Mining Dengan Algoritma Apriori Pada RDBMS Oracle,2003,Jurnal Penelitian dan Pengembangan TELEKOMUNIKASI, Juni 2003, Vol. 8 No. 1,3. http://elib.unikom.ac.id/files/disk1/487/jbp tunikompp-gdl-derrisepti-24335-2babii_dx. pdf, 23 Januari 2017.

[9] Gunadi, Goldie, Sensue, Indra , Dana Penerapan Metode Data mining Market Basket Analysis Terhadap Data PenjualanProduk Buku Dengan Menggunakan Algoritma Apriori Dan Frequent Pattern Growth (FP-Growth): Studi Kasus Percetakan PT.Gramedia,121-122). (2012).. 